\title{
NOTAS SOBRE CAPITALISMO DEPENDENTE BRASILEIRO E POLÍTICA DE SAÚDE (1988-2020**
}

\author{
Valentina Sofía Suárez. Baldo \\ Arthur Lobo Costa Mattos
}

\section{Introdução}

O presente capítulo é uma primeira tentativa de organização das ideias para contar a história do SUS, utilizando o marco teórico-metodológico da Teoria Marxista da Dependência (TMD). Faz parte de um esforço coletivo, organizado em torno do Grupo de Pesquisa Saúde, Sociedade, Mercado e Estado (SEM), vinculado ao Instituto de Medicina Social (IMS) da Universidade do Estado do Rio de Janeiro (UERJ) ${ }^{1}$.

A história do SUS, estabelecido pela Constituição Federal de 1988, é articulada à trajetória da seguridade social, das políticas sociais, das lutas de classes, do desenvolvimento capitalista brasileiro e de seu caráter dependente. Metodologicamente, combinam-se análises quantitativas e qualitativas, baseadas em levantamento bibliográfico da literatura acadêmica sobre os assuntos e séries históricas de longa duração. Para a análise, se utilizam referenciais teóricos da TMD, sobretudo a produção recente, de autores como Jaime Osorio, Carla Ferreira e Mathias Luce. Informações de caráter estatístico são recolhidas de múltiplas fontes, usando tanto organismos nacionais e internacionais quanto literatura acadêmica de diferentes abordagens.

Evitando excessiva simplificação, busca-se oferecer uma visão sinóptica, sintética e sistemática de elementos que se consideram indispensáveis para uma análise das políticas de saúde. Os elementos inter-relacionados a serem considerados são: "[a.] a natureza de nossa formação social diante da forma atual da sociedade capitalista mundial, [b.] sobre o que isto implica para a dinâmica da luta de classes e por último, [c.] para o caráter de classe do Estado e a forma política do Estado no Brasil" (IASI, 2019, p. 433; sem grifo e sem ordenação no original). Nesta apresentação, a formação social brasileira será entendida como um tipo de capitalismo dependente; o foco será dado à correlação de forças, ao se abordar a luta de classes; e à intervenção na saúde, ao tematizar o Estado.

Tais elementos envolvem múltiplas instituições e processos sociais seculares, mantendo entre si, como ressaltado acima, influências mútuas. Configuram um sistema complexo, cujos nexos serão investigados aqui, exploratoriamente, a partir de suas simultaneidades e trajetórias histórico-geográficas. Parte-se de conceitos e categorias (abstrações) consagrados na literatura da abordagem escolhida, servindo-se de séries históricas de informações estatísticas para uma aproximação dos temas tratados, por contraste ou ilustração. Trata-se de esboçar um quadro cronológico, com finalidade didática e sugestões bibliográficas para aprofundamento dos assuntos. Espera-se que o modesto panorama apresentado reforce a produção em andamento e facilite a interlocução tanto dentro do campo de pesquisa quanto com teorias rivais.

\footnotetext{
* DOI- 10.29388/978-65-81417-27-7-0-f.27-46

1 Os autores agradecem a orientação do professor Paulo Henrique de Almeida Rodrigues. Destacam, no entanto, que o conteúdo do capítulo é de inteira responsabilidade deles.
} 
O capítulo está dividido em duas partes, além desta introdução e das considerações finais. Inicialmente, apresenta-se a proposta teórica marxista sobre a dependência, indicando como ela aborda os elementos em jogo (a formação social, a luta de classes e o Estado no capitalismo dependente brasileiro), oferecendo uma visão geral, indicando como a TMD entende o contexto histórico em questão. Na parte subsequente, mostra-se como a análise da intervenção estatal na saúde se compatibiliza com a leitura histórica proposta, seguindo uma ordem cronológica de exposição, que divide o período tratado na pesquisa (1988-2020) em três momentos (entre 1988 e 1995; 1995 e 2015, e 2015 e 2020), detalhando, para cada momento, características do Estado dependente vigente presentes no SUS.

\section{Abordagem teórico-metodológica da pesquisa}

Como dito, a abordagem adotada neste trabalho seguirá os aportes da Teoria Marxista da Dependência (TMD) e produções relacionadas, no interior da tradição marxista latinoamericana. ${ }^{23}$

O ponto de partida metodológico da TMD são as críticas marxista e leninista das teorias do valor e do imperialismo, em diálogo crítico com elaborações marxistas diversas, como as produções europeias contemporâneas de Althusser e Poulantzas. Sempre tomando por referência o modo de produção capitalista tal qual formulado, em um alto nível de abstração, por Karl Marx, seus teóricos investigam as relações internacionais e a economia política em niveis de abstração menores, levando em conta fenômenos mais concretos, ao nível das formações econômicosociais (com suas estruturas política, econômica, social, ideológica) e da economia mundial (com suas relações militares-diplomáticas, comerciais e políticas). Além disso, propõem um nível de abstração intermediário para as investigações, o de padrão de reprodução do capital (o qual visa apreender, de modo articulado, a produção, circulação, acumulação, distribuição e apropriação, em conjunturas históricas específicas).

Nas investigações da TMD, a análise de classes das formações sociais é central, buscando uma visão da totalidade, que não fragmente a vida social em compartimentos (evitando pensar o social separado da história; o político, do econômico; o econômico, do antropológico; a história, da geografia etc.). Ainda que análises parciais possam ser desenvolvidas como momentos da investigação, trata-se de uma análise que leva em conta simultaneamente: a estrutura e o desenvolvimento das forças produtivas e das relações de produção; o movimento da sociedade, suas lutas de classes, os choques entre grupos minimamente conscientes e organizados; as culturas, instituições, ideologias existentes (BAMBIRRA, 2015).

\footnotetext{
2 Alguns trabalhos de caráter introdutório, são: BAMBIRRA, V. (2015). O capitalismo dependente latino-americano; FERREIRA, C. (2012). Padrão de reprodução do Capital; LUCE, M. S. (2018). Teoria Marxista da Dependência; OSORIO, J. (2019). Estado no centro da mundialização. A narrativa realizada neste capítulo se baseia fortemente nestas referências.

${ }^{3}$ A TMD nasceu como leitura alternativa das relações internacionais e da economia política, realizada por acadêmicos membros da chamada nova esquerda latinoamericana das décadas de 1960-1970, fundamentando uma proposta política revolucionária, anti-imperialista e imediatamente socialista. (LUCE, 2018, p. 208). Colocava-se em contraposição à leitura que a maior parte da esquerda latinoamericana fazia desses temas antes da instauração de ditaduras na região, leitura, grosso modo, de base cepalina, de cunho nacional-desenvolvimentista, conciliatório e reformista, da qual Celso Furtado (1920-2004) era o maior expoente. Realizou a princípio o que se pode entender como uma crítica da crítica que a CEPAL fazia da economia política liberal vigente - então keynesiana. Desenvolveu-se inicialmente em Brasília, encabeçada por três brasileiros: Vânia Bambirra (1940-2015), Ruy Mauro Marini (1932-1997) e Theotonio dos Santos (1936-2018), e um estrangeiro, o estadunidense-alemão Andre Gunder Frank (19292005). Na década de 1970, em paralelo ou com contatos não-sistemáticos, outros grupos de pesquisa no Rio de Janeiro e São Paulo, igualmente com abordagem marxista, convergiram com os resultados desse impulso inicial, com destaque para a obra do sociólogo paulista Florestan Fernandes (1920-1995), que já havia maturado seu marxismo.
} 
$\mathrm{Na}$ análise da estrutura produtiva e relações de produção, a industrialização é o principal indicador de mudanças de qualidade. Bambirra (2015), na construção de sua tipologia das formações sociais latino-americanas, justifica a escolha deste critério apontando que desde a primeira Revolução Industrial, o sentido do desenvolvimento de qualquer sociedade passou a ser dado pela indústria manufatureira; em outras palavras, a ideia de desenvolvimento aparece intimamente associada à industrialização. Onde ocorre, o processo de industrialização tende a subordinar os outros setores da economia à indústria e se transforma no elemento central da dinâmica de desenvolvimento econômico, político e social.

\subsection{0 que é a dependência?}

Define-se a dependência como uma dupla articulação, entre uma situação de dependência nas relações internacionais e a estrutura socioeconômica dependente de uma formação econômico-social, articulação que se dá seguindo movimentos dialéticos. Por um lado, a situação de dependência externa condiciona a conformação de uma estrutura socioeconômica, tornando-a dependente. Por outro lado, essa estrutura condicionada, para se desenvolver de modo capitalista (ou seja, socializando a produção, privatizando os ganhos e mercantilizando a vida), leva ao limite leis econômicas imanentes ao capitalismo, apresentando tendências particulares de desenvolvimento, próprias de um capitalismo dependente. Esta estrutura, com suas leis tendenciais particulares, por sua vez, reage à situação dependente condicionante, reforçando ou afrouxando ${ }^{4}$ os laços político-econômicos e a complementaridade assimétrica entre países centrais/imperialistas e periféricos/dependentes.

As leis tendenciais particulares que se desenvolvem nestas formações sociais são expressões das leis do capitalismo ${ }^{5}$ levadas ao seu limite, "com toda sua brutalidade" (MARINI, 1991 apud LUCE, 2018). As leis tendenciais específicas no capitalismo dependente, destacadas por Luce (2018), são a transferência de valor como intercâmbio desigual, a superexploraşão da força de trabalho e a cisão do ciclo do capital. Pelo caráter sintético desta exposição, não entrar-se-á em detalhes sobre elas, serão apenas ressaltados aspectos necessários à argumentação.

A transferência de valor como intercâmbio desigual é investigada através de fenômenos como a deterioração dos termos de intercâmbio, remessas de juros, royalties e dividendos ao exterior e apropriação de recursos naturais por monopólios, que expressam traços de dependência comercial, financeira e tecnológica, no âmbito da divisão internacional do trabalho. Estudando esses fenômenos, entendidos como intercâmbio desigual ou de não-equivalentes (não ocorrendo o nivelamento da taxa de lucro), compreende-se como eles resultam em relações desfavoráveis duradouras, de subordinação, nas quais economias imperialistas se apropriam de valor/riqueza, transferidos/perdidos pelas economias dependentes (LUCE, 2018).

Uma das medidas que a burguesia dependente utiliza para compensar essa transferência de valor e perda de riqueza, ocasionada pela tendência anterior, é tornar a superexploração da força de trabalho, uma possibilidade conjuntural onde quer que haja capitalismo, numa tendência estrutural e sistemática do capitalismo dependente. A superexploração da força de trabalho,

\footnotetext{
${ }^{4}$ A possibilidade de afrouxamento dos laços de dependência se dá somente em determinadas formações sociais e em conjunturas excepcionais, de crises e guerras mundiais, como no conturbado período de 1914 a 1955.

${ }^{5}$ Começando pela lei geral, segundo a qual quanto maiores forem as riquezas sociais e, consequentemente, o proletariado e a força produtiva, tanto maior será o exército industrial de reserva e, consequentemente, a superpopulação relativa e a pobreza ("pauperismo") (MARX, 2013 p. 719).
} 
entendida como pagamento pelo trabalho abaixo do seu valor, como o prolongamento da jornada e o aumento da intensidade do trabalho além de limites normais, provocam o desgaste prematuro dos trabalhadores, a redução de suas vidas, transformando o fundo de consumo do trabalhador em fundo para acumulação.

O desenvolvimento capitalista provoca fissuras no ciclo do capital (produçãodistribuição-consumo), entre a estrutura produtiva e a circulação de mercadorias, entre a produção de bens "de luxo" ("suntuários") e as demandas e necessidades de consumo, gerando desequilíbrios, impasses e contradições. No caso do capitalismo dependente, por suas relações com a circulação de capital dos países centrais, essas fissuras tornam-se cisões no ciclo do capital. Constituídas historicamente, essas cisões ocorrem inicialmente entre o mercado interno e externo e, posteriormente, no caso das formações sociais dependentes que se industrializaram, entre as esferas alta e baixa de consumo no mercado interno. Configura-se assim uma repartição sui generis do mais-valor entre setores produtores, que se materializa numa industrialização não orgânica a sua própria estrutura econômica e numa integração subordinada ao mercado mundial. Junto à superexploração, essa tendência explica o "divórcio entre a estrutura produtiva e as necessidades das massas", tão característico da América Latina (LUCE, 2018, p. 85).

As leis tendenciais no capitalismo dependente oferecem explicações, considerando longos períodos de tempo, do porquê de a América Latina permanecer "estagnada" economicamente, ser uma das regiões mais desiguais, com parcelas enormes da população vivendo em condições de péssima infraestrutura, sem direitos constituídos e/ou com direitos violados e expropriados, ainda que exista industrialização (com substituição de importações) e urbanização. Ao contrário dos efeitos esperados por teorias desenvolvimentistas e apostas políticas de centro-esquerda e progressistas, para as quais o crescimento econômico capitalista implicaria progressivamente a diminuição da desigualdade e da pobreza, a TMD mostra que quanto mais desenvolvimento capitalista nos países dependentes, mais dependência, demonstrando que o imperialismo é um fenômeno também interno e um elemento constitutivo do capitalismo latino-americano.

\subsection{Generalidades, particularidades e centralidade do Estado no capitalismo dependente}

A TMD segue a leitura de Marx e Engels acerca do Estado, que

[...] articula, de maneira orgânica e dialética, economia, política e [...] a dimensão social, [...] destacando o caráter de classe do Estado, relacionando poder político e econômico e revelando suas contradições [...] bem como a centralidade do Estado, enquanto principal fator de coesão de uma organização social (BICHIR, 2017, p. 43).

Cabe destacar aqui que o Estado não apenas ocupa um lugar central na estrutura jurídicopolítica e no sistema de poder social (com seus aspectos nacionalistas, classistas, racistas e sexistas), mas também um lugar destacado na estrutura econômica e seus múltiplos sistemas (incluindo o sistema de saúde). Por uma parte, importa sublinhar que o Estado é extremamente importante em seu papel ou função contraditória de oferecer não apenas as contratendências às leis gerais do capitalismo, mas também de sustentar as leis tendenciais específicas do capitalismo dependente, a começar pela superexploração da classe trabalhadora (que envolve, por exemplo, 
os altos patamares de desemprego como pressão ao rebaixamento dos salários). Por outra parte, não se pode esquecer que somente através do Estado "se cristaliza a hegemonia política e a definição dos projetos e modelos econômicos e políticos que prevalecem. Somente o Estado tem a capacidade de apresentar interesses sociais limitados como interesses societários de toda a comunidade" (OSORIO, 2019, p. 220).

Como lembra Fontes (2017, p. 16-17), a configuração do Estado é uma das dimensões do capitalismo contemporâneo. Pode ser definido por "uma correlação de forças entre classes", respondendo "às tensões e às lutas sociais intraclasses dominantes e entre as classes sociais". A finalidade fundamental do Estado capitalista é "a preservação da forma de ser social predominante, isto é, aquela que reproduz o próprio capital" e "a garantia da permanência da dominação de classes". Este é o caráter de classe do Estado.

Conforme sugere Osório (2019, p. 205), “o Estado no capitalismo dependente está atravessado pelo menos por dois processos que definem suas particularidades", redefinindo as características gerais do Estado capitalista. O primeiro deles é o processo de subsoberania, definido pela condição dependente das formações sociais; o outro é a superexploração da força de trabalho, por seu efeito sobre as relações entre classes, frações e setores.

O Estado dependente é caracterizado, externamente, por uma soberania frágil, que tem, como contraparte interna, democracias restringidas (LUCE, 2018, p. 231). Merece destaque a subordinação/associação das classes dominantes locais (nacionais) em relação às classes dominantes imperialistas (o que não exclui conflitos), resultando no enfraquecimento e mesmo na ausência de projetos autônomos de desenvolvimento ou nacionais. Os processos de monopolização e integração, mais recentes, provocaram uma reduzida expansão das classes dominantes, compensada pelo autoritarismo e internalização das relações de poder de Estados centrais e imperialistas.

Nos capitalismos dependentes, as relações de classe estão baseadas na superexploração do trabalho, com tendência ao aumento da população trabalhadora pobre e miserável, esgotada física e mentalmente, subempregada ou desempregada, o que, por si só, já torna as contradições entre classes mais agudas. A cisão do ciclo do capital, por meio da qual geram-se processos produtivos voltados ao exterior ou a um mercado interno restrito, ignorando as necessidades da maioria da população, acentua ainda mais estas contradições (MARINI, 1991 apud LUCE, 2018). Mesmo que latente, há alto nível de conflito social, com fraturas sociais e, consequentemente, "exercício férreo do poder político", em que "mecanismos coercitivos operam de forma recorrente" (OSORIO, 2019, p. 208-209).

Por tudo isso, o Estado no capitalismo dependente ganha relevância, ocupa um lugar central. Diante da barbárie predominante e da fragilidade social, se por um lado o Estado não produz sentido de comunidade (relegado, em grande parte, à religião), por outro, é idealizado como refúgio ou autoridade protetora, concomitantemente a uma tendência à despolitização. A debilidade produtiva, a restrição de opções dada a condição dependente, coloca a importância do intervencionismo, negado sistematicamente pela submissão política ao mercado, regido pelos grandes monopólios, entendido como agente neutro. 


\subsection{Síntese da evolução histórica do Estado dependente}

Apresentar-se-á agora o quadro sintético da leitura histórica da TMD sobre o Estado, a partir do qual se buscará compreender a história do SUS, ou seja, da reorganização do subsistema estatal da saúde, após 1988.

Conforme sugere Osorio (2019), é possível periodizar os processos políticos (incluindo o Estado) a partir das correlações de forças (relações entre agrupamentos de dominantes e agrupamentos de dominados, com uma diversidade de forças no interior de cada um deles). Essa periodização tem a vantagem de que esta variável integra outras, como o bloco no poder e a hegemonia (quem detém o poder e qual é seu projeto social hegemônico ou padrão de reprodução proposto) e as formas de governo (como se exerce o poder).

A formação econômica brasileira tem, entre seus traços distintivos, a industrialização, um processo alongado, que dura pouco mais de um século, entre o terço final do século XIX e o final do século XX, quando advém um período de desindustrialização (relativa). Nos termos de Bambirra (2015), o Brasil passou de uma formação capitalista-exportadora dependente, no final do século XIX, para uma capitalista-industrial dependente, no primeiro terço do século XX. Atualmente há a recondução a um padrão exportador, porém com especialização produtiva, sem eliminar completamente o setor industrial, readequando-o.

A importância do Estado no capitalismo dependente se demonstra pela relevância que teve na modificação de padrões de reprodução do capital. Do final do século XX até o presente, numa situação internacional de crises e hegemonia estadunidense, aberta com os "choques do petróleo" (1973-79), em uma correlação de forças na qual a grande burguesia, associada ao capital monopolista estrangeiro, se impôs, ocorreu a transformação do Estado de contrainsurgência (a ditadura militar-empresarial-eclesiástica) para um Estado neoliberal (uma democracia liberal, ao menos formalmente). O Estado de contrainsurgência, que viabilizou um padrão de reprodução industrial restrito com integração monopólica ao capital estrangeiro, foi substituído por um Estado neoliberal, que fundamenta um padrão exportador com especialização produtiva (OSORIO, 2019; LUCE, 2018). Este Estado neoliberal está orientado pela austeridade nas políticas sociais, processos de privatização variados e militarização das forças de segurança. Os efeitos sociais dessa transformação são bem representados pelo novo patamar que o desemprego alcançou: ainda que os dados possam ser criticados e mais bem colocados, é ilustrativo o crescimento da taxa de desemprego, que, entre 1972 e 1990, teve seu ponto mais alto em 4,83\% (1982) e o mais baixo em 1,92\% (1976), saltando para uma variação entre 10,21\% (1999) e 6,03\% (1993) de 1992 a 2014 (WORLD BANK, 2021).

A passagem a essa nova experiência de democracia restringida se deu a partir de uma mudança da correlação de forças, com uma recomposição organizativa das classes trabalhadoras, numa Estratégia Democrático-Popular (EDP) (que combinaria ocupação do Estado com mobilização popular, acumulando forças para, em outro momento, realizar uma ruptura societária, a princípio socialista e democrática) (IASI et al., 2019). À medida que os operadores políticos da EDP ampliaram a representação no Estado (com destaque para a sequência de eleições presidenciais do PT), alargou-se progressivamente seu leque de alianças até incluir a grande burguesia (IASI, 2006). Sem perder uma gama de operadores políticos possíveis (com importante lugar do PSDB), o grande empresariado e o setor financeiro, por sua vez, apostaram num "ativismo empresarial-político burguês" (FONTES, 2017a, p. 207), através de uma "malha de entidades sem fins lucrativos" (FONTES, 2017b, p. 16). Enquanto isso, aumentava a 
violência do Estado, o "genocídio do negro brasileiro" (FERNANDES, 1976; 2016), expresso pelo aumento da população vivendo em áreas com pouca ou nenhuma infraestrutura urbana e do encarceramento em massa. A trajetória parece confirmar a permanência da autocracia, reunindo a democracia de cooptação (impulsionada por uma burguesia corruptora) com recrudescimento do despotismo burguês (FERNANDES, 1976; IASI, 2014).

O entrelaçamento das estratégias das classes em conflito, além de uma descrença na política (FONTES, 2017a), resulta no enfraquecimento organizativo da classe trabalhadora, mesmo com ocorrência recente das maiores manifestações de massa da história e um movimento grevista só comparável com os anos finais da redemocratização (DIEESE, 2021). A partir de 2014, a grande burguesia (expressa nas milhares de organizações setoriais), pressiona por mudanças macroeconômicas, que resultam numa elevação do patamar de desemprego, indo para os altos níveis de 11,6\% em 2016 e 13,69\% em 2020 (WORLD BANK, 2021). Aproveitando-se do contexto de corrupção (e de combate à corrupção, em escala mundial), numa manobra envolvendo o judiciário, a grande mídia e as forças armadas, com vínculos e apoios estrangeiros, principalmente estadunidenses, o grande empresariado brasileiro desencadeia uma crise no interior do agrupamento dominante, reorganiza o sistema político, instaurando um Estado de Segurança com verniz eleitoral (OSORIO, 2019). A manobra e a nova forma estatal, que tem semelhanças com o ocorrido em Honduras e Paraguai, realiza nova sequência de contrarreformas (trabalhistas e sindicais, nas políticas sociais, como previdência, saúde e educação) e privatizações, indicando uma radicalização do modelo neoliberal, com a participação explícita e crescente das forças armadas nos poderes da República e um processo de autonomização/insubordinação das forças policiais.

Com essa breve síntese, compreende-se que o SUS emerge no fim do Estado de contrainsurgência e no advento do Estado neoliberal e acompanha, atualmente, a mudança para um Estado de segurança com verniz eleitoral. Nunca é demais lembrar a histórica conquista do direito à saúde pelas classes trabalhadoras brasileiras, uma vitória gigantesca, seja no cenário latino-americano ou mundial, sendo o Brasil um dos poucos países com mais de 100 milhões de habitantes a ter um sistema estatal dessa monta. De qualquer forma, seu desenvolvimento, sua expansão e consolidação não foi uma exceção nem rompeu os limites do neoliberalismo do Estado dependente, como, tampouco, parece impedir a constituição de um Estado de Segurança (como demonstra a recente militarização do Ministério da Saúde).

Isso significa dizer que, sem negar a expansão do SUS durante o período democrático, algumas das principais características do Estado neoliberal (sua austeridade e privatização) se fizeram presentes. O Estado de segurança que se instaura, entre outros aspectos, parece incluir uma radicalização dessas características. Assim, a interpretação dessa mudança de forma do

Estado dependente pode ser ilustrada com séries históricas de dados que permitam uma visualização da expansão do subsistema público, do seu financiamento e dos processos de privatização e relação com o setor privado. Dar-se-á preferência a informações que possam ressaltar a dimensão geográfica dessas dinâmicas.

\section{O Estado dependente na Saúde (1988-2020)}

Nesta seção, explora-se a dinâmica da intervenção estatal na saúde, dentro dos marcos do capitalismo industrial-dependente em padrão de reprodução do capital exportador com 
especialização produtiva, tomando, como referências, características do Estado neoliberal e de Segurança com verniz eleitoral: sua austeridade e privatização. No que se refere à austeridade, presume-se que, mesmo ocorrendo uma reorganização e expansão do subsistema público, este encontra-se cronicamente subfinanciado. Acerca da privatização, considera-se que há um setor privado consolidado e processos de privatização do público, assim como inserção de mecanismos de mercado, em andamento.

A investigação preliminar aqui realizada aproxima-se do movimento de expansão do SUS, a partir da composição de gastos e do seu arcabouço institucional; do seu subfinanciamento crônico, por meio da análise das fontes de financiamento e seus arranjos institucionais, enfatizando aqueles que implicaram perda de recursos, esboçando algumas comparações com outros países; e dos processos de privatização e da relação com o setor privado, pela análise dos setores de planos e seguros privados e da gestão de serviços públicos de saúde. ${ }^{6}$

\subsection{Transição política-econômica e emergência do Estado neoliberal (1988 - 1995)}

Até a criação do SUS, incluído na Constituição Federal de 1988 (CF88) junto a outros direitos sociais, o serviço público de saúde no Brasil era precário e insuficiente para a grande maioria, enquanto um setor minoritário da sociedade tinha acesso à assistência médica previdenciária (por estar vinculado ao mercado formal de trabalho) ou podia comprar planos e seguros de saúde privados. Os recursos públicos para a saúde eram executados pelo Ministério da Saúde e pelo Instituto Nacional de Assistência Médica da Previdência Social (INAMPS), principal instituição da assistência médica previdenciária à época. Até 1988, o modelo assistencial dominante era o da medicina hospitalar e da medicina ambulatorial de especialidades, centrada em grandes hospitais nas capitais e cidades de médio porte. A Atenção Primária à Saúde pública era modesta, "basicamente restrita aos Postos de Saúde que, em sua grande maioria, prestavam serviços relacionados a pacotes assistenciais e voltados para uma seleção de problemas de saúde; além disso, assistência à gestante, puericultura básica e vacinação.” (ANDERSON, 2019, p. 2). O Estado de contrainsurgência, com uma série de medidas, havia modificado o sistema de saúde brasileiro, numa direção que favoreceu o crescimento do setor privado dentro da saúde, distanciando-o de sua matriz corporativista, que perdurava e se complexificava desde a década de 1930.

O período 1988 a 1995 correspondeu ao momento da definição legal, da regulamentação dos direitos que haviam sido estabelecidos na CF88. Em relação ao SUS, uma das primeiras medidas foi a transferência do INAMPS para o Ministério da Saúde, iniciada em 1989 (BUSS, 1995; GERSCHMAN, 1995) e encerrada em 1993, quando o instituto foi legalmente extinguido (CARVALHO, 1995; GUGLIELMI, 2006). Em 1990, foram aprovadas as duas primeiras leis de regulamentação do SUS: a Lei no 8.080, Lei Orgânica da Saúde, e a Lei no 8.142, que dispôs sobre a participação da comunidade na gestão do SUS e transferências de recursos. No entanto, apenas aprovadas, sofreram múltiplos vetos do governo neoliberal do presidente Fernando Collor (RODRIGUES; SANTOS, 2011; VIANA, 1995). Mais tarde, as Normas Operacionais Básicas (NOB), de 1991, 1992 e 1993, operacionalizaram os princípios constitucionais do SUS: respectivamente, dispuseram sobre Conselhos de Saúde (VIANA, 1995; CARVALHO, 1995),

\footnotetext{
${ }^{6}$ Nesta oportunidade não se aborda a expansão da exploração capitalista nos setores de prestação de serviços e de produção e circulação de bens de saúde.
} 
sobre critérios para o repasse de recursos para os municípios (GERSCHMAN, 1995) e sobre normas e procedimentos reguladores do processo de descentralização da gestão das ações e serviços de saúde (BRASIL, 1993). A operacionalização do sistema se encerrou somente em 1998, quando a NOB 1996 - cuja execução havia sido protelada por dois anos - efetivou o SUS, ao regulamentar as transferências fundo a fundo entre o governo federal, estados e municípios, pondo em prática o princípio de descentralização administrativa.

Apesar dos avanços na regulamentação, o SUS enfrentou instabilidade nas fontes de financiamento e insuficiência de recursos desde sua criação. A implementação dos preceitos constitucionais implicava gastos crescentes; no entanto, a opção do governo Collor foi a retração de gastos e a tentativa de desconstitucionalizar direitos: entre 1991 e 1992, o ajuste fiscal conduziu à contração do gasto social (KERSTENETZKY, 2012). Em relação aos gastos com saúde, a participação do setor no total das receitas próprias federais caiu de 18,9\%, em 1989, para 9,15\%, em 1993 (LEVCOVITZ, 1997). O cálculo dos recursos destinados ao setor saúde, que estava previsto no Ato das Disposições Constitucionais Transitórias, não foi cumprido pela equipe econômica do governo federal e não se manteve na Lei de Diretrizes Orçamentárias, depois de 1993 (SOARES; SANTOS, 2014). Nesse mesmo ano, o ministro da Previdência Social cancelou a transferência de recursos da Previdência para o SUS, no contexto de uma crise previdenciária, trilhando o caminho da instabilidade e incerteza das fontes de financiamento do sistema (GOULART, 2001).

A criação do SUS significou o estabelecimento de um subsistema público integrado, capilarizado e com fontes de financiamento definidas, que iria beneficiar, principalmente, aqueles sem cobertura previdenciária ou privada, a maior parte da classe trabalhadora. No entanto, os seguros e as prestações privadas de serviços seguiram sendo importantes. A taxa de cobertura de planos de saúde já era alta quando da criação do SUS: em 1987, era de $20 \%$ da população, chegando ao patamar de 25\% em 1994 (ALMEIDA, 1998). No momento da formulação do sistema, "a força do setor privado levou a uma negociação legislativa que estabeleceu o setor como complementar ao público" (COHN, 2008 apud LAURELL, 2016. p. 304). Assim, os seguros de saúde passaram a compor o que se denominou como saúde suplementar. Apesar da intenção de ser único, o sistema de saúde permaneceu segmentado após a reforma, coexistindo nele dois subsistemas: o SUS e a saúde suplementar - ou três, considerando a estrutura de assistência médica dos integrantes das Forças Armadas e outros servidores públicos, que permaneceu corporativista -, com distintas modalidades de financiamento, afiliação e provisão de serviços de saúde, cada um destinado a diferentes estratos sociais da população, de acordo com a sua inserção laboral, nível de renda e capacidade de pagamento.

\subsection{O Estado dependente neoliberal (1995-2015)}

As duas décadas compreendidas entre 1995 e 2015 correspondem à progressiva implementação e expansão da Seguridade Social criada na CF88. Posterior à Reforma do Estado, de 1995, o gasto social, embora crescente, esteve marcado por reformas retracionistas na previdência e influenciado pelas recomendações sociais do FMI, que enfatizavam o combate à pobreza e a implantação de programas básicos dentro de políticas universais (KERSTENETZKY, 2012). A expansão constante da cobertura de seguros (em um alto patamar), o avanço da gestão privada do público, via organizações sociais sem fins lucrativos, e a 
difusão geográfica da estrutura administrativa do SUS caracterizam este período, corroborando a leitura de um entrelaçamento entre estratégias de classes antagônicas.

O gasto social público total teve uma tendência de crescimento quase uniforme no período, passando de 11,5\% do PIB, em 1995, a 17,7\%, em 2018 (CEPALSTAT, 2019). No setor de saúde, dados do período de 2000 a 2017 mostram que o gasto público geral em saúde, como porcentagem do PIB, acompanhou essa tendência de crescimento, passando de 3,8\% em 2000 a 5,2\% em 2017, o que representa um aumento de 36,8\% (CEPALSTAT, 2019). Se medido em relação ao gasto total em saúde, o gasto público geral em saúde também cresceu, embora de forma muito mais modesta: passou de 41,63\% em 2000 a 42,91\% em 2015" (WORLD BANK, 2021a). A execução orçamentária do Ministério da Saúde com ações e serviços de saúde também apresentou uma evolução crescente entre 1995 e 2009, praticamente dobrando o valor total do gasto entre esses anos (MACHADO, 2012).

A extensão territorial do sistema atesta a expansão ocorrida. A NOB/96, implementada somente em 1998, deu início ao efetivo funcionamento do SUS. A norma regulamentou as transferências fundo a fundo entre governo federal, estados e municípios, efetivando a descentralização administrativa. Indicadores da evolução da descentralização, a partir da $\mathrm{NOB} / 93$ e da NOB/96, mostram que o número de municípios habilitados a receber recursos fundo a fundo multiplicou mais de 700 vezes entre 1997 e 1998, passando de 144 a 5.049. No mesmo período, a porcentagem da população residente em municípios habilitados aumentou de 17,3\% para 89,9\% (SILVA; LIMA, 2005). O Programa Saúde da Família (PSF), que desde sua criação, em 1994, elevou a atenção básica ao patamar de política de Estado, capilarizou o SUS no território brasileiro no período, passando de atuar em 55 municípios, em 1994, a estar presente em 4.494, em 2004, multiplicando sua presença territorial mais de 80 vezes em 10 anos (SILVA; LIMA, 2005). Em 2006 ocorreu a publicação do Pacto pela Saúde, cujas diretrizes respondiam à necessidade de realizar mudanças nas formas de relacionamento estabelecidas entre as esferas de governo (LIMA; QUEIROZ, 2005). O Pacto sistematizou os repasses, orientando-os para a consolidação da atenção primária como eixo estratégico e organizativo do SUS. O PSF, que evoluiu para Estratégia de Saúde da Família (ESF), aumentou expressivamente a cobertura populacional da política de atenção primária, passando de cerca de 10\%, em 1998, para 74\% da população brasileira, em 2019 (ANDERSON, 2019). Outra importante expansão do período foi a do Programa Farmácia Popular do Brasil, criado em 2004 (PAULA et. al., 2009; SILVA, 2014). O número de farmácias "próprias" do programa cresceu de 27 em 2004 para 543 em 2010, enquanto o número de farmácias privadas conveniadas, cuja incorporação foi permitida em 2006, cresceu de 2.955, no primeiro ano, para 14.003 em 2010, registrando um impressionante aumento de 373,8\% (MACHADO; BAPTISTA, 2012). Por fim, um outro marco histórico da expansão territorial e populacional do SUS, nos seus primeiros 30 anos, foi o Programa Mais Médicos (PMM). Criado em 2013, visava resolver um problema crônico da saúde no Brasil: a alocação de profissionais para a prática da APS em regiões remotas e nas periferias dos grandes centros urbanos, territórios vulneráveis do ponto de vista socioeconômico. Em 2015, mais de 18 mil profissionais do PMM estavam presentes em $81 \%$ dos municípios brasileiros, em todas as capitais de estados, em todos os 34 Distritos Sanitários Especiais Indígenas (DSEI), cobrindo 63 milhões de brasileiros em condições de elevada vulnerabilidade (ANDERSON, 2019).

Neste período, simultâneo à expansão do SUS, no contexto de um Estado contrarreformado (BEHRING, 2003), foram desviadas e extintas fontes de recursos do sistema, criados e retirados mecanismos de contribuição e introduzidas mudanças nas regras de financiamento, fatores estes 
que colaboraram para o subfinanciamento crônico do SUS e sua instabilidade financeira, pelo menos até a regulamentação da Emenda Constitucional 29/00, em 2012. Em 1996, foi criada a Contribuição Provisória sobre a Movimentação Financeira (CPMF) para o financiamento do SUS (DRAIBE, 2003; DAIN, 2007). No entanto, essa mesma fonte de recursos passou a ser compartilhada com a Previdência, em 1999, e com o Fundo de Combate à Pobreza, em 2001 (DAIN, 2007). Finalmente, em 2007, a CPMF foi extinta, secando essa fonte de financiamento do SUS (PRATES; FARHI, 2009). Além disso, foram criados dispositivos para a retirada dos recursos destinados à saúde, como a Desvinculação de Receitas da União (DRU), em 2000, a qual, na prática, permite que o governo aplique os recursos destinados a áreas como educação, saúde e previdência social em qualquer despesa considerada prioritária (como na formação de superávit primário ou no pagamento de juros da dívida pública). A DRU foi prorrogada diversas vezes e tem vigência prevista até 2023, podendo desvincular do destino constitucional, atualmente, 30\% da arrecadação (AGÊNCIA SENADO, 2021). Em 2000, foi aprovado um marco na história do SUS, a Emenda Constitucional no 29, que alterou a definição das fontes de financiamento originais do sistema, estabelecidas na CF1988, determinando mínimos a serem gastos pela União, estados e municípios na área da saúde (RODRIGUES; SANTOS, 2009; DRAIBE, 2003; DAIN, 2007). A EC 29/00 foi regulamentada somente em 2012, outorgando alguma estabilidade ao financiamento do sistema (GOMES, 2014), mais de 20 anos depois da criação do SUS. Em contrapartida, a lei da regulamentação não fixou percentual a ser aplicado pela União em Ações e Serviços Públicos de Saúde (ASPS), reforçando o subfinanciamento do SUS (SOARES; SANTOS, 2014).

Considerando o período em questão (1995-2015), Soares e Santos (2014) mostram que, do ponto de vista do comportamento dos gastos com saúde, no âmbito federal, os governos do PT não diferiram dos governos do PSDB. Para Marques et al. (2018), nos anos de Lula da Silva e Dilma Rousseff, “apesar do gasto público ter melhorado [...] o nível do gasto público com saúde continuou insuficiente, bem abaixo da média praticada nos países com sistemas públicos similares (8\%), o que resulta num gasto per capita bastante baixo" (MARQUES et al., 2018). À guisa de exemplo, os gastos públicos em saúde, como porcentagem do gasto total do governo no período de 2000 a 2008, oscilaram entre 4,1\% (2000) e 6\% (2008), sendo que nos países da Organização para a Cooperação e o Desenvolvimento Econômico (OCDE), esses mesmos gastos aumentaram ano a ano, crescendo de 13,8\% (2000) para 15,7 (2008) (WHO, 2010 apud GADELHA; COSTA, 2012).

No âmbito do setor privado, sua robustez e fortalecimento durante este período são patentes. A taxa de cobertura de planos de saúde (assistência médica) parece ter mantido uma certa estabilidade em todo o período, se consideradas séries históricas que podem não ser equivalentes. Kilsztajn et al. (2001), utilizando dados do IBGE, aponta que, passados os primeiros 10 anos de SUS, os seguros privados já alcançaram uma cobertura de 24,4\% da população (em 1998). Por outra parte, dados da ANS (2021) mostram que, em dezembro de 2000, a taxa de utilização de seguros era de 18,1\%, com um crescimento ininterrupto entre 2003 e 2015 , quando chegaria ao patamar de $25,8 \%$ (ANS, 2021). Destaca-se entre os determinantes do desenvolvimento do setor privado a renúncia fiscal decorrente da dedução dos gastos com planos de saúde no Imposto de Renda, criada no período da ditadura e ampliada no governo de Fernando Henrique Cardoso, que na prática funciona como um incentivo do governo federal à saúde privada, na forma de redução de Imposto de Renda a pagar, por parte de pessoa física 
ou jurídica, aplicada sobre despesas com plano de saúde e/ou médicas e similares (MENDES; WEILLER, 2015). Para Marques et. al. (2018), nos governos do PT esses determinantes foram mantidos e mesmo aprofundados.

Uma das consequências da (contra)Reforma do Estado no setor de saúde, que expressa a estratégia das classes dominantes de atuação via "terceiro setor", foi a privatização da gestão pública dos serviços, que teve expressiva expansão, através da criação de organizações sociais sem fins lucrativos (OSs) e outros tipos de pessoas jurídicas de direito privado responsáveis pela administração de hospitais e unidades de saúde, mecanismo que foi ironicamente incluído no chamado Programa Nacional de Publicização, implementado em 1998. Em 1999, outra lei qualificou pessoas jurídicas de direito privado sem fins lucrativos como organizações da sociedade civil de interesse público (OSCIP). Essas modalidades de privatização inserem no setor público modelos de desempenho e custos próprios da iniciativa privada (MONTEIRO, 2020), modificando o processo de trabalho na saúde. Segundo dados do IPEA (2018 apud MONTEIRO, 2020), entre 1981 e 1990 o Brasil registrava 88.147 organizações sociais sem fins lucrativos; depois do Programa Nacional de Publicização e da lei das OSCIPs, foram criadas mais 478.841 organizações dessa natureza.

Atualmente são 820.186 organizações da sociedade civil, e dentre essas, 6.841 administram hospitais e unidades de saúde pelo Brasil. Embora seja um quantitativo pequeno em relação ao universo total, é no campo da saúde que está o maior volume financeiro e também a maior quantidade de empregos formais, totalizando 112.048 postos de trabalho (MONTEIRO, 2020, p. 4).

Na mesma época em que, por meio do Programa Nacional de Publicização, se permitiu a criação de OSs para atuar no setor da saúde, a NOB/96 expandia os serviços de saúde através da determinação de formas e incentivos para a descentralização dos serviços. Pouco depois, foi sancionada a Lei de Responsabilidade Fiscal (em 2000), que limitou a contratação de pessoal pelos níveis de governo, criando o paradoxo em que os estados e municípios, ao mesmo tempo em que foram encarregados de prestar serviços de saúde, foram impedidos (ou limitados) de prestar tais serviços diretamente à população (MONTEIRO, 2020). Nesse contexto, a contratação de OSs para administrar o serviço de saúde público se tornou uma alternativa para "driblar" a limitação imposta pela Lei de Responsabilidade Fiscal, porque a contratação de trabalhadores realizada pelas OSs não entra na conta de despesas com pessoal. Esta interação entre o Programa Nacional de Publicização, que criou as OSs, a NOB/96, que incentivou a descentralização dos serviços de saúde e a Lei de Responsabilidade Fiscal, que limitou a contratação de recursos humanos se configurou um estímulo estatal à privatização da gestão da saúde. A extensão da questão merece destaque: em torno de $10 \%$ dos municípios brasileiros possuem estabelecimentos sob sua responsabilidade administrado por terceiros, sendo importante considerar que, segundo as informações do Atlas dos Municípios, em 2014, "entre os 39 municípios com mais de 500000 habitantes, 22 deles (56,4\%) contrataram serviços por meio de Organizações Sociais" (IBGE, 2014, p. 61). 


\subsection{Estado de segurança do grande capital com verniz eleitoral (2015-2020)}

Respondendo à ofensiva econômica e política das classes trabalhadoras, entre os anos de 2012 e 2016, a grande burguesia, associada ao capital estrangeiro, com fusões cada vez mais profundas de interesses, desencadeia o processo social em andamento, mediante manobras midiáticas, jurídicas e militares, colocando-se a necessidade do Estado dependente mudar de forma. Com o sentido de uma derrota para a classe trabalhadora, uma sequência de modificações no Estado, em diversos âmbitos, político-institucionais, trabalhistas, etc., incluindo a saúde, indicam a emergência de um Estado de Segurança. Modificações na dinâmica de características do Estado dependente na saúde confirmam essa mutação, que tem semelhanças com o Estado de contrainsurgência. A impossibilidade de avanço social, com destaque para o novo patamar do desemprego (WORLD BANK, 2021), confirma a leitura da TMD, de que mais desenvolvimento, implica mais dependência.

Neste último período de análise, embora o gasto em saúde tenha se mantido estável, ocorreram mudanças regressivas em relação a conquistas do período anterior. O gasto social público total cresceu, passando de 16,3\% do PIB, em 2015, para 17,7\%, em 2018 (CEPALSTAT, 2019). O gasto público geral em saúde, como porcentagem do gasto total em saúde, apresentou leve decréscimo no período, sendo 42,96\% em 2016 e 41,67\% em 2018" (WORLD BANK, 2021a).

A edição de 2017 da Política Nacional de Atenção Básica (PNAB) representou um retrocesso para a concepção de APS que havia sido um relativo consenso por mais de 20 anos. Esta nova versão da PNAB permitiu maior flexibilização na implementação de modelos de APS, relativizando a prioridade tradicionalmente dada à ESF, descaracterizando e desvirtuando a proposta dos Núcleos de Apoio à Saúde da Família, em um contexto de teto de gastos, apontando para uma ambulatorização da atenção primária. Pouco tempo depois, a atenção básica sofreria um novo golpe com o projeto de criação do Programa Saúde na Hora, em 2019, que visa transformar Unidades de Saúde da Família em unidades de pronto-atendimento nos municípios de médio e grande porte (ANDERSON, 2019).

Desde o governo de Michel Temer, devido ao estremecimento das relações diplomáticas e da cooperação Brasil-Cuba por divergências ideopolíticas, a participação dos médicos cubanos no Programa Mais Médicos (PMM), mediada pela Organização Panamericana da Saúde (OPAS), tornou-se instável. Culminou no encerramento abrupto da cooperação e, logo depois, do programa, no início de 2019. A importância que o PMM tinha na distribuição geográfica do SUS (e da assistência médica) pode ser demonstrada pelo déficit de médicos em $42 \%$ dos municípios do país após seu encerramento, particularmente naqueles mais remotos e com piores indicadores socioeconômicos (REIS, 2019). Existe o projeto de substituição do PMM pelo Programa Médicos Pelo Brasil, apresentado pelo governo de Jair Bolsonaro, também em 2019, que, no entanto, traz retrocessos em relação à formação por meio de residências médicas, à participação das universidades no desenvolvimento da ESF e ao escopo de ações desenvolvidas pela APS (ANDERSON, 2019)

Ainda que o gasto público geral em saúde, como porcentagem do PIB e como porcentagem do gasto total em saúde, tenha se mantido estável no período, o financiamento do SUS sofreu um golpe demolidor: em 2016, a Emenda Constitucional $\mathrm{n}^{\mathrm{o}} 95$ determinou o congelamento por 20 anos dos gastos da União nas áreas da saúde e educação, agudizando o problema do subfinanciamento crônico do SUS, indicando um desfinanciamento a médio e 
longo prazo. A medida retirou 20 bilhões de reais do SUS, em 2019, sendo que a projeção do Cebes é de que a perda seja de 168 bilhões de reais até 2036 (MONTEIRO, 2020). Cabe lembrar que no ano anterior, na Emenda Constitucional $n^{\circ}$ 86/2015, que instituiu a obrigatoriedade de execução das emendas parlamentares, havia sido incluída nova regra para a aplicação dos recursos do governo federal na saúde, alterando a base de cálculo anteriormente existente (montante apurado no ano anterior corrigido pela variação nominal do PIB) por um percentual da Receita Corrente Líquida (RCL). No primeiro ano (2016) seria 13,2\% da RCL, até alcançar $15 \%$. Isso resultou em perda de recursos para o SUS de R $\$ 9,2$ bilhões já no primeiro ano (FUNCIA, 2015 apud MARQUES et al., 2018, p. 538).

Uma forma de definir o subfinanciamento do SUS é a partir do indicador gasto público com saúde como percentual do PIB, comparado a países com sistemas públicos de saúde semelhantes. Na comparação, o baixo nível registrado no país configuraria o subfinanciamento do SUS (MARQUES, 2017). Fazendo um exercício um pouco diferente, de comparação do Brasil com México e Argentina - por serem países do capitalismo dependente com industrialização parecida e, junto com o Brasil, os mais industrializados da América Latina, porém com sistemas de saúde diferentes - e com os Estados Unidos (EUA), como medida de comparação mundial, nota-se que o gasto público geral em saúde, como porcentagem do PIB, no Brasil é um dos mais baixos: em 2018, o gasto público geral em saúde nos EUA era de 8,51\% do PIB; na Argentina, 5,91\%; no Brasil, 3,96\%; e no México, 2,69\%" (WORLD BANK, 2021b).

No advento do Estado de Segurança, o setor privado parece ter chegado ao limite de sua expansão nos marcos anteriores. O gasto privado em saúde, como porcentagem do gasto total em saúde teve um leve aumento no período analisado com marcas de 57\% em 2015 e 58,24\% em 2018 (WORLD BANK, 2021c). Comparando uma vez mais com Argentina, México e EUA, esse indicador no Brasil é alto, sobretudo se considerado o fato de que é o único país com sistema público universal da seleção: em 2018, o gasto privado em saúde, como porcentagem do gasto total, no México era de 49,92\%; nos EUA, 49,58\%, e na Argentina, 38,29\%" (WORLD BANK, 2021c). A taxa de cobertura de planos de saúde (assistência médica) encerrou seu crescimento, se mantendo estável (com leve decréscimo). No período, observa-se a maior taxa de utilização de seguros privados (25,8\% em 2015) (ANS, 2021). Hoje (2021), 24,7\% da população é beneficiária de planos de saúde (ANS, 2021), com acesso diferenciado a consultas, exames e leitos hospitalares. Abrindo novo espaço para o privado no interior do público, em 2015, uma lei passou a autorizar a entrada do capital estrangeiro na atenção à saúde (acrescentando-se a liberação da atuação na intervenção privada, estipulado em 1998), introduzindo exceções à vedação constitucional à participação direta ou indireta de empresas ou capitais estrangeiros nas atividades de assistência à saúde. Até então, segundo a Constituição e a Lei Orgânica da Saúde, essa participação somente poderia ocorrer em casos excepcionais. A aprovação desta lei teve impacto no aumento da concentração das atividades em saúde e no SUS (MARQUES et al., 2018). Mais um mecanismo de privatização para o setor da administração e gestão pública da saúde foi proposto pela mesma medida provisória que projetou a implementação do Programa Médicos Pelo Brasil. Dessa vez, o plano supõe a criação da Agência para o Desenvolvimento da Atenção Primária à Saúde (ADAPS), que constitui "serviço social autônomo na forma de pessoa jurídica de direito privado com a finalidade de promover, em âmbito nacional, a execução de políticas da atenção primária à saúde" (BRASIL, 2019). 


\section{Considerações finais}

O presente capítulo procurou servir de preliminar, de incentivo, para o aprofundamento das questões levantadas. Indica o quadro geral teórico que orienta a leitura da história do SUS, trazendo alguns indicadores que ilustram dinâmicas sociais - sem levá-los às últimas consequências, ou seja, em uma etapa ainda prévia à colocação deles em termos estritamente marxistas. Há lacunas em diversas séries históricas consideradas (desemprego, composição de gastos em saúde, taxa de cobertura de planos de saúde, entre outras), bem como elipses argumentativas, devendo ser consideradas com mais calma e mais detalhadamente. Não há pretensão de novidade de diversos argumentos utilizados, em particular aqueles referentes à expansão, subfinanciamento e relações do SUS com o setor privado e privatizações, sendo necessário um melhor diálogo com a literatura e aprofundamento das questões.

Em um momento no qual o capitalismo brasileiro passa da industrialização seletiva, do fim do regime militar, para especialização produtiva exportadora atual, o SUS surge com o processo de democratização, quando a classe trabalhadora se reorganiza frente a grande burguesia imperante e seu Estado de contrainsurgência em distensão. Trata-se, ainda, de uma democracia restringida, de um Estado dependente em conformação neoliberal. Estado este que é uma peça central para a conformação de um padrão de reprodução do capital voltado à exportação, que limita a industrialização de uma formação social industrial-dependente. $\mathrm{O}$ Estado reorganiza-se, em torno de 1995, para adaptar-se ao neoliberalismo vigente, que estimula a financeirização, austeridade e variadas formas de privatização. Uma nova mutação estatal se verifica desde 2015, radicalizando os processos anteriores. Nesse contexto, a despeito da ampliação da atuação estatal, financiamento público e cobertura do setor público de saúde, que significou a criação do SUS, somada à abertura de um enorme espaço sócio-ocupacional para assistentes sociais e outras categorias profissionais, ocorreu simultaneamente a privatização, a introdução de mecanismos de mercado, que no campo do trabalho se traduziu em múltiplas formas de precarização, como terceirização, fragilidade do vínculo trabalhista, demissões em massa e baixos salários, que agora radicalizam-se.

\section{Referências}

AGENCIA NACIONAL DE SAÚDE SUPLEMENTAR (ANS). Taxa de Cobertura de Planos de Saúde. 2021. Disponível em: http://www.ans.gov.br/anstabnet/cgibin/tabnet?dados/tabnet_tx.def. Acesso em: 18 jun. 2021.

AGÊNCIA SENADO. DRU. 2021. Disponível em: https://www12.senado.leg.br/noticias/entenda-o-assunto/dru. Acesso em: 19 jun. 2021.

ALMEIDA, C. O Mercado Privado de Serviços de Saúde no Brasil: Panorama Atual e Tendências da Assistência Médica Suplementar. Instituto de Pesquisa Econômica Aplicada. Texto para discussão n. 599. Brasília, Instituto de Pesquisa Econômica Aplicada, novembro de 1998 
ANDERSON, M. I. P. Médicos pelo Brasil e as políticas de saúde para a Estratégia Saúde da Família de 1994 a 2019: caminhos e descaminhos da Atenção Primária no Brasil. Rev. Bras. Med. Fam. Comunidade, v. 14, n. 41, p. 2180, 2019. Disponível em: https://www.rbmfc.org.br/rbmfc/article/view/2180/998. Acesso em: 19 ago. 2020.

BAMBIRRA, Vânia. O capitalismo dependente latino-americano. 3. ed. Florianópolis: Insular, 2015.

BEHRING, E. R. Brasil em contra-reforma: desestruturação do Estado e perda de direitos. São Paulo: Cortez, 2003.

BICHIR, M.M. 2017. A questão do Estado na Teoria Marxista da Dependência. Tese (doutorado) - Universidade Estadual de Campinas, Instituto de Filosofia e Ciências Humanas Unicamp Campinas, SP, 2017. 205p.

BRASIL. Ministério da Saúde. Portaria n. 545, de 20 de maio de 1993. Estabelece normas e procedimentos reguladores do processo de descentralização da gestão das ações e serviços de saúde, através da Norma Operacional Básica - SUS 01/93. Disponível em: https://bvsms.saude.gov.br/bvs/saudelegis/gm/1993/prt0545_20_05_1993.html. Acesso em: 19 jun. 2021.

BRASIL. Medida Provisória n. 890, de 01 de agosto de 2019. Institui o Programa Médicos pelo Brasil e a Agência para o Desenvolvimento da Atenção Primária à Saúde. Brasília, DF: Presidência da República, [2019]. Disponível em: http://www.planalto.gov.br/ccivil_03/_ato2019-2022/2019/Mpv/mpv890.htm. Acesso em: 23 abr. 2021.

BUSS, P. M. Saúde e Desigualdade: o Caso do Brasil. In: BUSS, P. M. (Org.). Sistemas de Saúde, continuidades e mudança. Rio de Janeiro: FIOCRUZ/HUCITEC, 1995.

CARVALHO, A. I. Conselhos de Saúde no Brasil, participação cidadã e controle social. Rio de Janeiro: IBAM/FASE, 1995.

CASTRO, A. L. B.; FAUSTO, M. C. R. A Política Brasileira de Atenção Primária à Saúde. In: MACHADO, C. V.; BAPTISTA, T. W. F.; LIMA, L. D. (Org.). Políticas de Saúde no Brasil: continuidades e mudanças. Rio de Janeiro: Editora Fiocruz, 2012. p. 173-197.

CEPALSTAT. Gasto público según clasificación por funciones del gobierno (en porcentajes del PIB). 2019. Disponível em:

https://estadisticas.cepal.org/cepalstat/tabulador/ConsultaIntegrada.asp?idIndicador=3127\&idi oma $=$ e. Acesso em: 18 jun. 2021.

CONSELHO NACIONAL DE SECRETÁRIOS DE SAÚDE (CONASS). Assistência farmacêutica no SUS. Brasília: CONASS, 2007. 
DAIN, S. Os vários mundos do financiamento da saúde no Brasil: uma tentativa de integração.

Ciência \& Saúde Coletiva, 12(Sup), p. 1851-1864, 2007.

DEPARTAMENTO INTERSINDICAL DE ESTATÍSTICA E ESTUDOS

SOCIOECONÔMICOS (DIEESE). Número de greves (1983-2020), Brasil. Balanço das

greves de 2020. Estudos e pesquisas n. 99 - 10 de maio de 2021.

DRAIBE, S. A política social no período FHC e o sistema de proteção social. Tempo Social, São Paulo, v. 15, n. 2, p. 63-101, nov. 2003.

FERNANDES, F. A revolução burguesa no Brasil. Ensaio de interpretação sociológica. Rio de Janeiro: Zahar Editores, 1976.

FERNANDES, F. Prefácio à edição brasileira. In: NASCIMENTO, A. O genocídio do negro brasileiro. São Paulo; Perspectivas, 2016

FERREIRA, C.; OSORIO, J.; LUCE, M. S. 2012. Padrão de reprodução do capital. Contribuições da Teoria Marxista da Dependência. São Paulo: Boitempo, 2012.

FLEURY, S. Reforma sanitária brasileira: dilemas entre o instituinte e o instituído. Ciência \& Saúde Coletiva, Rio de Janeiro, v. 14, n. 3, p. 743-752, maio/jun. 2009.

FONTES, V. O Brasil e o capital-imperialismo. Rio de Janeiro: EPSJV, UFRJ, 2010.

FONTES, V. 2017a. Prefácio. in DANTAS, A. V. Do socialismo à democracia: tática e estratégia na Reforma Sanitária Brasileira. Rio de Janeiro: Editora Fiocruz, 2017.

FONTES, V. 2017b. Hegemonismos e política. in MATTOS, M. B. (Org.) Estado e formas de dominação no Brasil contemporâneo. Rio de Janeiro: Consequência Editora, 2017.

GADELHA, C. A. G.; COSTA, L. S. Saúde e Desenvolvimento Nacional: a gestão federal entre 2003 e 2010. In: MACHADO, C. V.; BAPTISTA, T. W. F.; LIMA, L. D. (Org.). Políticas de Saúde no Brasil: continuidades e mudanças. Rio de Janeiro: Editora Fiocruz, 2012. p. 61-90.

GERSCHMAN, S. A democracia inconclusa. Um estudo da reforma sanitária brasileira. Rio de Janeiro: Editora FIOCRUZ, 1995.

GOMES, F. B. C. Impasses no financiamento da saúde no Brasil: da constituinte à regulamentação da emenda 29/00. Saúde Debate, Rio de Janeiro, v. 38, n. 100, p. 6-17, jan/mar. 2014.

GOULART, F. A. A. Esculpindo o SUS a golpes de portaria: considerações sobre o processo de formulação das NOBs. Ciência \& Saúde Coletiva, v. 6, n. 2, p. 292-298, 2001. 
GUGLIELMI, M. C. V. A política pública 'Saúde da Família' e a permanência - fixação do profissional em medicina: um estudo de campo em Pernambuco (Tese de doutorado). Rio de Janeiro: IMS/UERJ, 2006, 215 p.

IASI, M. L. As metamorfoses da conciência de classe: o PT entre a negação e o consentimento. 1. ed. São Paulo: Expressão Popular, 2006

IASI, M. L. O inventário da estratégia democrática popular e a busca de um caminho para a revolução brasileira. In: IASI, M. L.; FIGUEIREDO, I. M.; NEVES, V. (Org.). Estratégia democrática popular: um inventário crítico. Marília: Lutas Anticapital, 2019. p. 431-439.

IASI, M. L. Estado, Ditadura e permanências: sobre a forma política. In: COUTINHO, E. G.; IASI, M. L. (Org.). Ecos do Golpe: a persistência da Ditadura 50 anos depois. 1ed. Rio de Janeiro: Morula, 2014. p. 81-106.

IASI, M. L.; FIGUEIREDO, I. M. (Org.) ; NEVES, V. (Org.) A estratégia democrática Popular. Marília: Lutas Anticapital, 2019.

INSTITUTO BRASILEIRO DE GEOGRAFIA E ESTATÍSTICA. Perfil dos Estados e dos Municípios Brasileiros. Perfil dos Municípios Brasileiros. Edição 2013. Rio de Janeiro: IBGE, 2014. 282p. Relatório técnico.

KERSTENETZKY, C. L. O estado do bem-estar na idade da razão. A reinvenção do estado social no mundo contemporâneo. Rio de Janeiro: Elsevier, 2012.

KILSZTAJN, S.; SILVA, D. F.; CÂMARA, M. B.; FERREIRA, V. S. Grau De Cobertura Dos Planos De Saúde E Distribuição Regional Do Gasto Público Em Saúde. Saúde e sociedade, v. 10, n. 2, p. 35-45, 2001. Disponível em:

https://www.scielo.br/j/sausoc/a/CwCB8qyKnXJ9nb3jNT7kwyP/?lang=pt. Acesso em: 19 jun. 2021.

LAURELL, A. C. Las reformas de salud en América Latina: procesos y resultados. Cuad. relac. Labor, v. 34, n. 2, p. 293-314, 2016. Disponível em: encurtador.com.br/tERS8. Acesso em: 19 mai. 2021.

LEVCOVTIZ, E. Transição x consolidação, o dilema estratégico do SUS: um estudo sobre as reformas da política nacional de saúde (Tese de Doutoramento). Rio de Janeiro: Instituto de Medicina Social, UERJ, 1997, 302 p.

LIMA, L. D.; QUEIROZ, L. F. N. O Processo de Descentralização e Regionalização do SUS no Contexto do Pacto pela Saúde. In: MACHADO, C. V.; BAPTISTA, T. W. F.; LIMA, L. D. (Org.). Políticas de Saúde no Brasil: continuidades e mudanças. Rio de Janeiro: Editora Fiocruz, 2012. p. 229-251.

LUCE, M. S. Teoria Marxista da Dependência. São Paulo: Expressão Popular, 2018. 
MACHADO, C. V. O Modelo de Intervenção do Estado na Saúde: notas sobre a atuação federal. In: MACHADO, C. V.; BAPTISTA, T. W. F.; LIMA, L. D. (Org.). Políticas de Saúde no Brasil: continuidades e mudanças. Rio de Janeiro: Editora Fiocruz, 2012. p. 117-147.

MACHADO, C. V.; BAPTISTA, T. W. F. A Agenda Federal da Saúde. In: MACHADO, C. V.; BAPTISTA, T. W. F.; LIMA, L. D. (Org.). Políticas de Saúde no Brasil: continuidades e mudanças. Rio de Janeiro: Editora Fiocruz, 2012. p. 149-171.

MARQUES, R. M. Notas exploratórias sobre as razões do subfinanciamento estrutural do SUS. Planejamento e Políticas Públicas, n. 49, p. 35-53, jul./dez. 2017. Disponível em: https://www.ipea.gov.br/ppp/index.php/PPP/article/view/950. Acesso em: 19 jun. 2021.

MARQUES, R. M.; XIMENES, S. B.; UGINO, C. K. Governos Lula e Dilma em matéria de seguridade social e acesso à educação superior. Revista de Economia Política, v. 38, n. 3 (152), p. 526-547, jul./set. 2018.

MARX, K. O capital: crítica da economia política: Livro I: o processo de produção do capital. São Paulo: Boitempo, 2013.

MENDES, A.; WEILLER, J. A. B. Renúncia fiscal (gasto tributário) em saúde: repercussões sobre o financiamento do SUS. Saúde Debate, Rio de Janeiro, v. 39, n. 105, p. 491-505, abr-jun 2015. Disponível em: https://www.scielosp.org/pdf/sdeb/2015.v39n105/491-505/pt. Acesso em: 19 jun. 2021.

MONTEIRO, N. O Estado em desmonte frente à epidemia da Covid-19. Physis: Revista de Saúde Coletiva, Rio de Janeiro, v. 30, n. 3, e300304, 2020. Disponível em: https://scielosp.org/article/physis/2020.v30n3/e300304/pt/\#. Acesso em: 19 set. 2020.

MORAES, E. L. Compras de medicamentos pelo Instituto Nacional de Câncer: análise do período 2007-2014. 2017. 372 p. Tese (Doutorado) - Instituto de Medicina Social, UERJ, Rio de Janeiro, 2017.

OSORIO, J. O Estado no centro da mundialização. São Paulo: Expressão Popular, 2019.

PAUlA, P. A. B.; ALVES, T. N. P.; VIEIRA, R. C.P. A.; SOUZA, A. I. S. Política de medicamentos: da universalidade de direitos aos limites da operacionalidade. Physis: Revista de Saúde Coletiva, Rio de Janeiro, v. 19, n. 4, p. 1111-1125, 2009.

PRATES, D. M.; FARHI, M. A crise financeira internacional, o grau de investimento e a taxa de câmbio do real. Texto para discussão n. 164. Campinas: UNICAMP, 2009.

REIS, V. Mais Médicos: Após saída de cubanos, 42\% das cidades têm vagas abertas. Abrasco, 27 mai. 2019. Disponível em: https://www.abrasco.org.br/site/noticias/opiniao/mais-medicosapos-saida-de-cubanos-42-das-cidades-tem-vagas-abertas/40961/. Acesso em: 19 jun. 2021. 
RODRIGUES, P. H. A.; SANTOS, I. S. Saúde e cidadania. Uma visão histórica e comparada do SUS. São Paulo: Atheneu, 2011.

SILVA, R. M. Programa "Aqui tem Farmácia Popular": expansão entre 2006-2012 e comparação com os custos da assistência farmacêujtica na Secretaria Municipal do Rio de Janeiro (Tese de doutoramento). Rio de Janeiro: IMS/UERJ, 2014, 291p.

SILVA, J. P. V.; LIMA, J. C. Sistema Único de Saúde: reafirmando seus princípios e diretrizes para fazer avançar a reforma sanitária brasileira. In: ESCOLA POLITÉCNICA JOAQUIM VENÂNCIO (Org.). Textos de apoio em políticas de saúde. Rio de Janeiro: Editora FIOCRUZ, 2005. p. 43-73.

SOARES, A.; SANTOS, N. R. Financiamento do Sistema Único de Saúde nos governos FHC, Lula e Dilma. Saúde Debate, Rio de Janeiro, v. 38, n. 100, p. 18-25, jan/mar. 2014.

VIANA, A. L. Modelos do Estado na área da saúde. Série Estudos em Saúde Coletiva n. 118. Rio de Janeiro: UERJ/IMS, 1995.

WORLD BANK. Domestic general government health expenditure $(\%$ of current health expenditure). 2020a. Disponível em: https://encurtador.com.br/ptDP5. Acesso em: 18 jun. 2021.

WORLD BANK. Domestic general government health expenditure ( $\%$ of GDP). 2020b. Disponível em: encurtador.com.br/rOSTY. Acesso em: 18 jun. 2021.

WORLD BANK. Domestic private health expenditure ( $\%$ of current health expenditure). 2020c. Disponível em: encurtador.com.br/oAIST. Acesso em: 18 jun. 2021.

WORLD BANK. Unemployment, total (\% of total labor force) (national estimate) - Brazil. (1972-2019). International Labour Organization, ILOSTAT database. Data retrieved on January 29, 2021. Dísponivel em: https://data.worldbank.org/indicator/SL.UEM.TOTL.NE.ZS?locations=BR. Acesso em: 19 jun. 2021. 